\title{
Folding Clothes Tool Using Arduino Uno Microcontroller and Gear Servo
}

\author{
Yuda Irawan ${ }^{1}$, Refni Wahyuni ${ }^{2}$, Hendry Fonda ${ }^{3}$ \\ 1, 2, 3 Department of Information System, STMIK Hang Tuah Pekanbaru, Pekanbaru, Indonesia \\ Email: ${ }^{1}$ yudairawan89@gmail.com, ${ }^{2}$ refniabid@gmail.com, ${ }^{3}$ fondaanda@gmail.com
}

\begin{abstract}
Folding clothes is one of the homework that is often done for housewives, from a survey conducted on 200 housewives in Pekanbaru, the problem is that many housewives choose to fold family clothes by hand, this takes time and the energy to do the job. Based on these problems, the authors designed a microcontroller with a servo motor as a practical medium in folding the clothes applied to the clothes folding tool, where the author uses the Hardware Programming Methodology in order to carry out this research smoothly, the materials needed in this research are Arduino Uno, Gear. Servo, Power Supply, and software components. The result of this research is the creation of an automatic clothes folding device that is useful for simplifying household chores. From the test results, it can be concluded that this tool can fold clothes with a duration of 2 seconds.
\end{abstract}

Keywords- Folding tools, Hardware Programming Methodology, Arduino Uno, Gear Servo, Ultra Sonic Sensor.

\section{INTRODUCTION}

The development of science and technology is currently very fast, and has a role in the advancement of human life. Electronic technology is one part of helping to ease human work. Various practical and efficient electronic devices have been created to help humans meet their needs was studied by baktiar[1]. Nowadays, various kinds of equipment that operate manually are increasingly being abandoned and switch to fully automatic equipment, so that automatic equipment dominates human life was studied by miller [2].

Housework is one of the most time-consuming activities was studied by Satya hariyanti [3]. Not only that, this activity is carried out every day, and of course when there is neglected homework it will be something that is lacking was studied by osawa [4]. One of the household chores that is a concern for this problem is folding dried clothes was stuied by fred [5]. When there are a lot of clothes, this will certainly take the time to fold and tidy up the clothes quickly and neatly, so that time for other activities is wasted was studied by doumanoglou [6].

From the above problems, a solution appears to ease wasted activity and time, for that a tool model is made that can help in folding clothes quickly with automatic labor was studied by erlangga [7]. The purpose of this research is to design a model for clothes folding device based on Arduino Uno and Gear Servo was studied by nurkholis [8]. It is hoped that this tool can provide benefits for solving solutions in terms of folding clothes in a relatively fast and neat time without having to fold manually by hand was studied by wahyuni [9]. So far, many people who fold clothes still use manual methods, namely using their bare hands was studied by hafis [10].

Based on the majority of people still folding clothes manually was studied by kido [11], in this study the author will design and make clothes folding device based on the Arduino Uno, the mechanism is fast moving with the help of Gear Servo and other components was studied by doumanoglou [12]. It is hoped that this tool can help shorten the time for folding clotheswas studied by ernawati [13].

\section{METHODS}

In conducting this research, the authors use the hardware programming method, the stages can be seen in the image in Fig. 1.

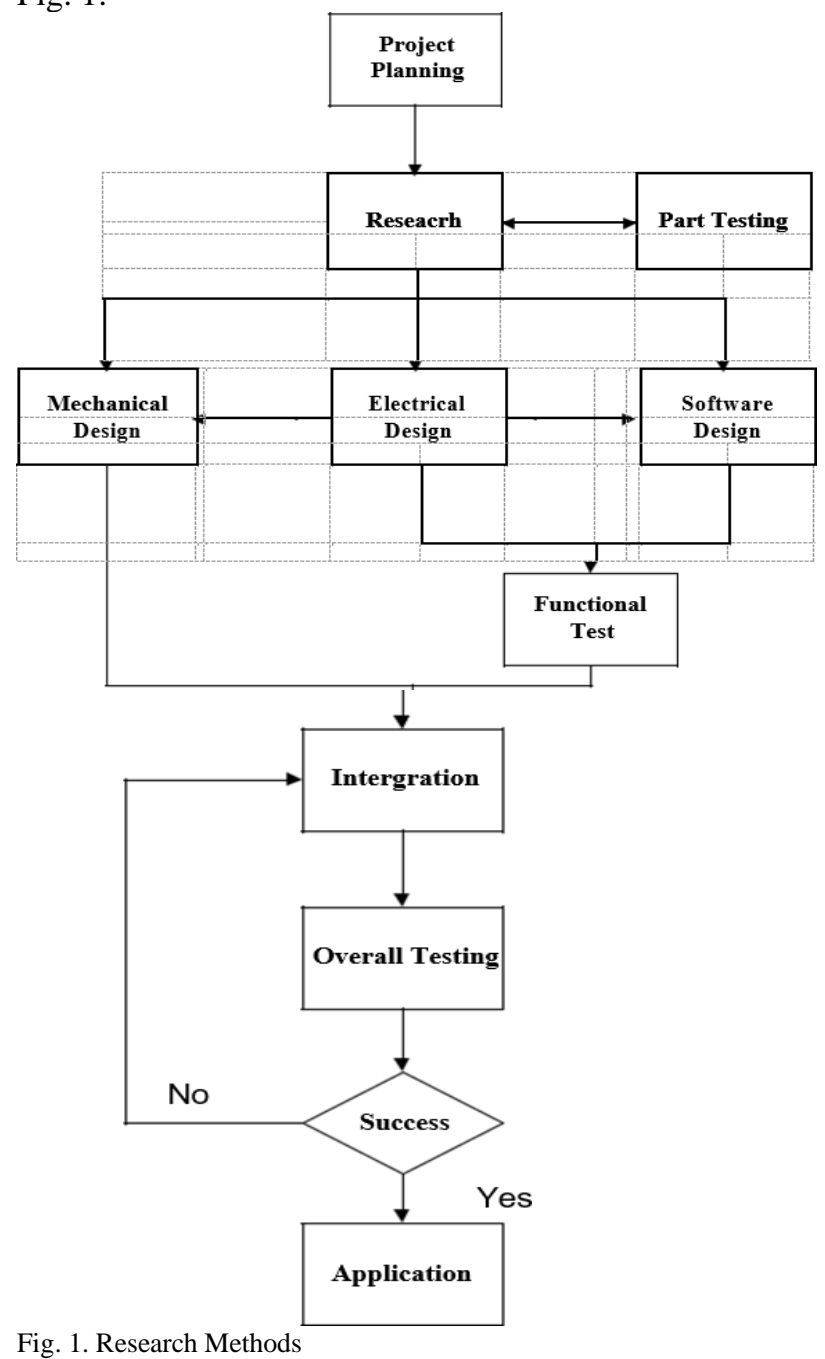




\section{A. Project Planning}

In planning a research project, there are several important things that need to be determined and considered was studied by Irawan [14], including:

1. Initial information on research;

2. Estimated needs for tools and materials;

3. Budget estimates, and,

4. Possible applications of the designed application was studied by luo [15].

\section{B. Research}

After the planning has been mature, it is followed by preliminary research on the application (hardware) to be made, starting from the selection and testing of components (tools and materials), the possibility of initial and final designs, namely the Arduino Uno-based Portable Clothes Folding Tool Model was studied by stria [16].

\section{Parts Testing}

In component testing, a tool testing is carried out on the function of the component based on the needs of the application to be made was studied by muhardi [17].

\section{Mechanical Design}

In hardware design, mechanical design is an important thing to consider, because it will affect the performance / results of the tools that have been made was studied by bukardi [18]. In general, the application requirements for mechanical designs include:

1. Shape and size of PCB (Printed Circuit Board)

2. Dimensions and mass of the entire system.

3. Resilience and flexibility to the environment.

4. Placement of the electronic modules.

5. Testing the mechanical system that has been designed was studied by pambudi [19].

\section{E. Electrical Design}

In the design of the electrical system, there are several things that must be considered, including:

1. Power supply source

2. The controller that will be used

3. Driver design for application support.

4. Design the control system to be applied.

5. Schematic model tool.

6. Flowchart design was studied by apriliyanto [20]

\section{F. Software Design}

Hardware generally requires software design for the tool control system which includes the system design to be used. The design of the software used in making this tool uses the Arduino IDE and Fritzing software was studied by zeng [21].

\section{G. Functional Test}

The functional test is carried out by integrating the electrical system and software that has been designed. This test is carried out to improve the performance of the software for controlling electrical designs and eliminate errors (bugs) from the software was studied by Irawan [22].

\section{$H$. Integration}

The electrical module is integrated with the software in the controller, integrated into the designed mechanical structure. Then a functional test of the entire system is carried out was studied by maitin [23].

\section{Overall Testing}

At this stage the function of the entire system is tested was studied by watanable [24].

\section{J. Application}

Application to improve the performance of applications that have been designed was studied by wahyuni [25]. Optimization is emphasized on the mechanical design for maximum and optimal use was studied by zhao [26].

\section{IMPLEMENTATION}

The Figure 2 is the framework used by the author to carry out this research using wooden boards.

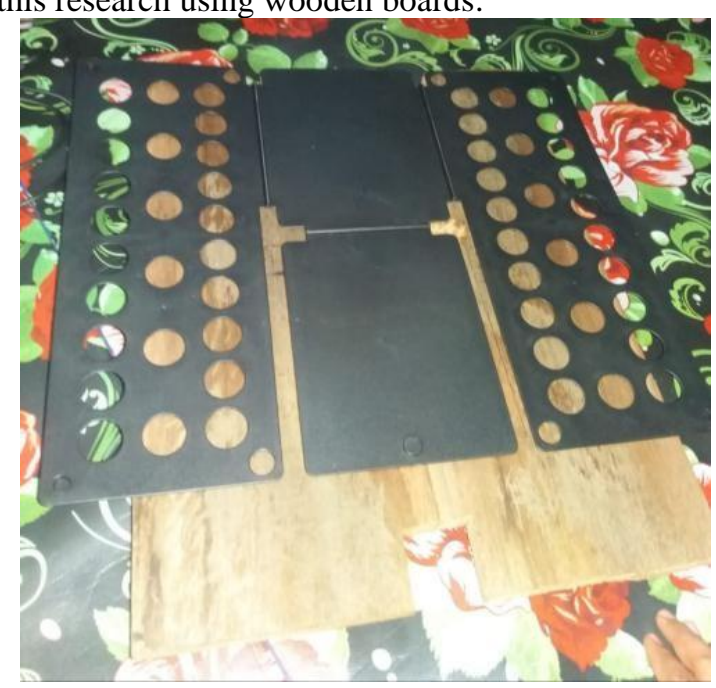

Fig. 2. Wood Frame

The wooden frame in Figure 3 is the main frame that will later house the Arduino Uno, Servo A, Servo B, Servo C, UltraSonic Sensors, Power Supply, and other components. All the components mentioned above are attached to a wooden board so that its functionality is more usable was studied by silitonga [27].

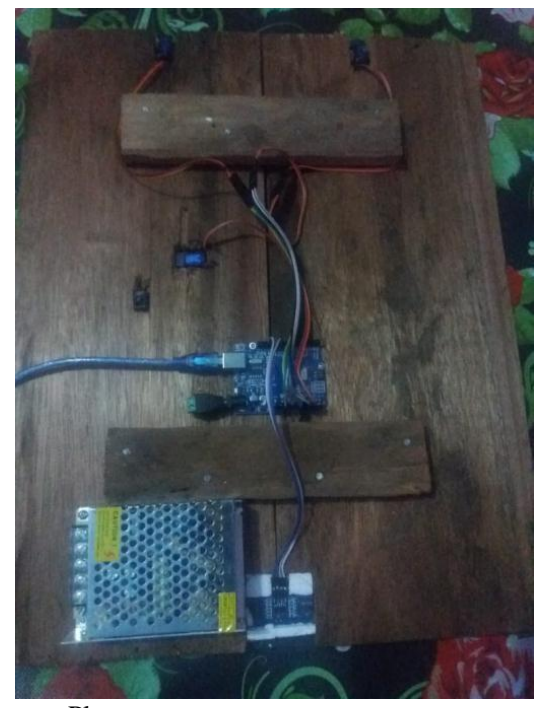

Fig. 3. Component Placement 
Regarding this, the placement of components on the frame, there are components such as Arduino Uno, Servo A, Servo B, Servo C, UltraSonic Sensor, Power Supply, and other components. All of the components mentioned above are attached behind this wooden axis, starting from the Power Supply which provides electricity to the Arduino Uno and then connected to several components such as ultrasonic sensors, servo A, B, C, so that the function can run smoothly by using this order was studied by Estevez [28]. The process of connecting tools and applications. Figure 4 is the process of coding the application and tools that will be created.

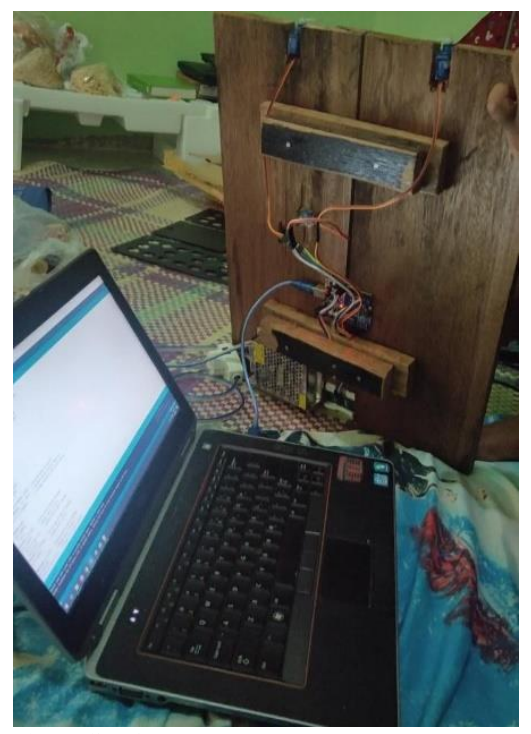

Fig. 4. Tools and Applications

Arduino IDE is an abbreviation of Integrated Development Environment which is a software for writing programs, compiling and uploading programs to the Arduino board. For basic applications using the Arduino IDE, the tools and materials used are: Computer, Arduino Uno board, USB cable was studied by zeng [29]. Arduino Ide implementation in Figure 5 is the coding used by the author to program the tools to be made:

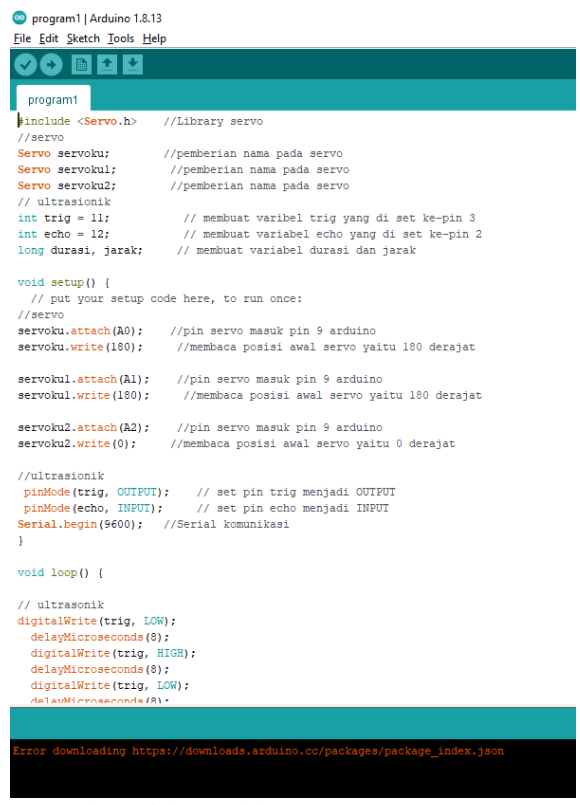

Fig. 5. Implementation of the Arduino IDE
After the IDE installation is complete, the Arduino will be ready to program. Programming is done using the Arduino IDE.To be able to program correctly, the Arduino IDE must be connected to the Arduino board which has been installed on a certain port, if it is connected then click Tools> Board> Arduino, then click Tools> Serial Port (depending on the port USB on the computer that we connect), After the settings are complete, the Arduino IDE is ready to use was studied by salleh [30].

Testing the coding used in Figure 6 is an explanation of the coding that will be used on the component devices that will be used:

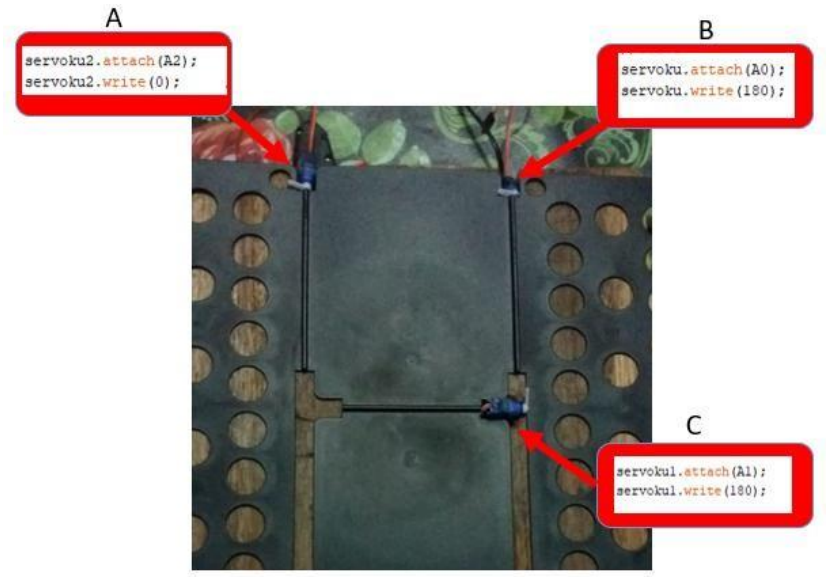

Fig. 6. Servo Coding

Include is the opening of this coding so that the program can be read, then coding A servoku2.write (0) to rotate the rotation position to the left from the upward servo position, in coding B servoku.write (180) to rotate right from the upward servo position, and in coding $\mathrm{C}$ servoku1.write (180) to rotate to the right from a sideways servo position was studied by yew [31].

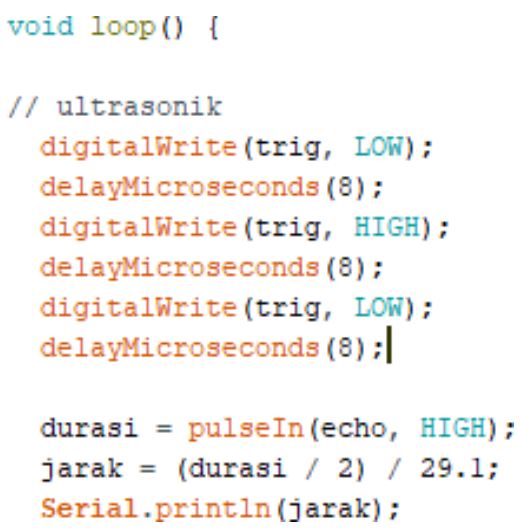

Fig. 7. Ultrasonic Coding

The coding above is an order of the speed of the ultrasonic duration, reading, and distance. duration = pulseIn (echo, $\mathrm{HIGH}$ ); useful for receiving ultrasonic sound, distance $=$ (duration / 2) / 29.1; useful for converting duration to distance (cm), Serial.println (distance); useful for displaying distance on a serial monitor. 


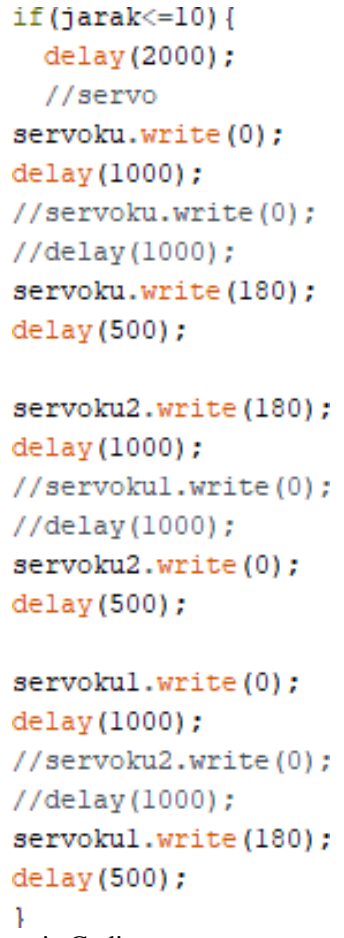

Fig. 8. Servo and Ultrasonic Coding

In the logic if (distance $<=10$ ) \{useful for detecting distance $(\mathrm{cm})$ from the ultrasonic eye, delay (2000); useful for the time it takes to read after an object arrives at the ultrasonic eye.

Servo A coding servoku2.write (180) is the servo position 0 degrees delay (1000); , servoku.write (0) the servo position will change to 180 degrees delay (500); , In the application servo B rotates from left to right.

Servo B coding servoku.write (0); is the servo position 180 degrees delay (1000) ; servoku.write (180) the servo position will change to 0 degrees delay (500); , In the application servo B rotates from right to left.

Servo C coding servoku.write (0); is the servo position 180 degrees delay (1000) ; servoku.write (180) the servo position will change to 0 degrees delay (500); , In the application servo B rotates from right to left.

Testing the whole circuit is a test of all systems from a series of tests for each of the previous series which are made into a single system and carried out procedurally for further system analysis process. The following is a picture of the overall system test in accordance with existing conditions.

\section{CONCLUSION}

After the author has finished testing, the results of the conclusions include the assembly of a clothes folding device in the form of a microcontroller with a servo drive that can be done with a minimum of 3 servo to 6 servos depending on the size requirements of the clothes. There are only 3 servo units and can only lift a small load of clothes, for clothes that are overloaded, it is recommended to add a total of 6 servo, installed on each opposite side of the existing servo placement. This tool can facilitate homework, namely in the work of folding clothes to be more efficient in time and energy.
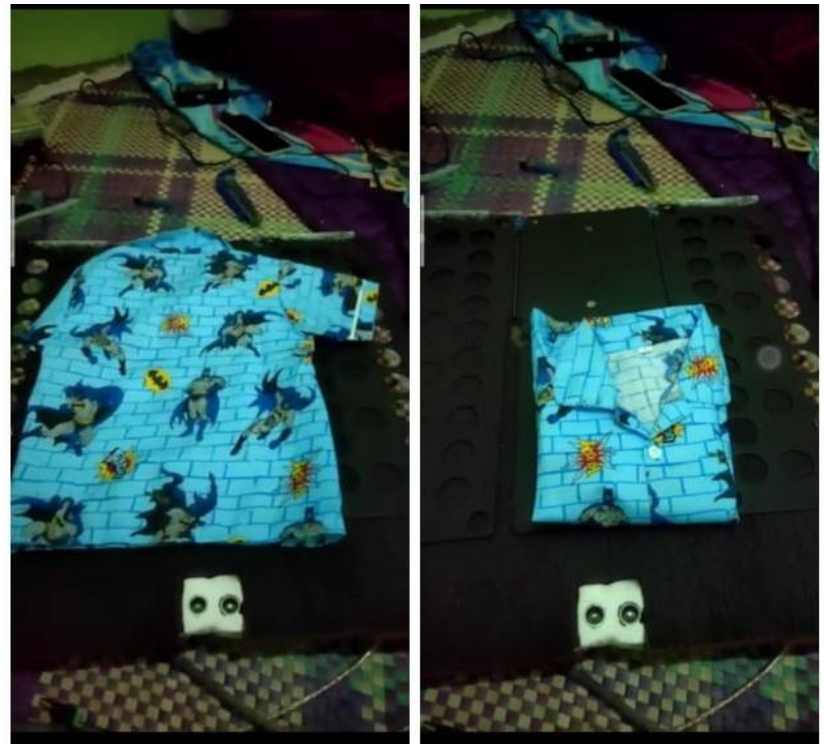

Figure. 9. Test Results

\section{REFERENCES}

[1] Satya Baktiar, I. K., \& Nugroho, P. W. Automatic clothes folding machine based on PLC (Proggammble Control Logic) as an alternative to help clothing activities. Final Project of Mechanical Engineering Department-Faculty of Engineering UM, 2017, Pp. 8689

[2] S. Miller, M. Fritz, T. Darrell and P. Abbeel, "Parametrized shape models for clothing," 2011 IEEE International Conference on Robotics and Automation, Shanghai, 2011, pp. 4861-4868, doi: 10.1109/ICRA.2011.5980453.

[3] Hariyanti, E., Tambunan, G., Saputra, R. A., Basjaruddin, N. C., \& Rakhman, E. Automatic clothes folding device with three microcontroller-based folding modes. In 2020 Proceedings of Industrial Research Workshop And National Seminar, 2020, Vol. 11, No. 1, Pp. 205-210.

[4] Osawa, F., Seki, H., \& Kamiya, Y. Clothes Folding Task By ToolUsing Robot. Journal Of Robotics And Mechatronics, 2006, 18(5), 618-625.

[5] Fred, H. U.S. Patent No. 2,071,257. Washington, Dc: U.S. Patent And Trademark Office, 2013,Pp 45-52.

[6] Doumanoglou, A., Stria, J., Peleka, G., Mariolis, I., Petrik, V., Kargakos, A., ... \& Malassiotis, S. Folding Clothes Autonomously: A Complete Pipeline. In 2016 Ieee Transactions On Robotics, 2016 32(6), 1461-1478.

[7] Erlangga, M. Automation of Arduino-Based Clothes Folding Machines Based on Patent No. 2,758,761 (In 2019 Doctoral Dissertation, University Of Muhammadiyah Malang), 2019, Pp 1-6.

[8] Nurkholis, A. M., \& Alfi, I. Automatic F-Cloth Smart Solution for Folding Clothes Practically Based on Arduino Uno (In 2018 Doctoral Dissertation, University Of Technology Yogyakarta), 2018.

[9] Wahyuni, Refni; Irawan, Yuda. Web-Based Employee Performance Assessment System in PT. Wifiku Indonesia. Journal of Applied Engineering and Technological Science (JAETS), 2020, 1.2: 60-69.

[10] Hafis, A. S. A. Design of Semi-Automatic Clothes Folding Machine Based on Arduino Uno (In 2019 Doctoral Dissertation, University Of Muhammadiyah Malang), 2019.

[11] M. Kido and H. Takahashi, "Clothing Model Fitting for Laundry Folding Assistance," 2019 Nicograph International (NicoInt), Yangling, China, 2019, pp. 37-40, doi: 10.1109/NICOInt.2019.00015.

[12] A. Doumanoglou et al., "Folding Clothes Autonomously: A Complete Pipeline," in IEEE Transactions on Robotics, vol. 32, no. 6, pp. 14611478, Dec. 2016, doi: 10.1109/TRO.2016.2602376.

[13] S. Ernawati, E. R. Yulia, Frieyadie and Samudi, "Implementation of The Naïve Bayes Algorithm with Feature Selection using Genetic Algorithm for Sentiment Review Analysis of Fashion Online Companies," 2018 6th International Conference on Cyber and IT 
Service Management (CITSM), Parapat, Indonesia, 2018, pp. 1-5, doi: 10.1109/CITSM.2018.8674286.

[14] Irawan, Yuda. "Implementation Of Data Mining For Determining Majors Using K-Means Algorithm In Students Of SMA Negeri 1 Pangkalan Kerinci." Journal of Applied Engineering and Technological Science (JAETS) 1.1 (2019): 17-29.

[15] J. Luo and T. Tjahjadi, "View and Clothing Invariant Gait Recognition via 3D Human Semantic Folding," in IEEE Access, vol. 8, pp. 100365-100383, 2020, doi: 10.1109/ACCESS.2020.2997814.

[16] J. Stria et al., "Garment perception and its folding using a dual-arm robot," 2014 IEEE/RSJ International Conference on Intelligent Robots and Systems, Chicago, IL, 2014, pp. 61-67, doi: 10.1109/IROS.2014.6942541.

[17] Muhardi, Muhardi, et al. "Design Of Web Based LMS (Learning Management System) in SMAN 1 Kampar Kiri Hilir." Journal of Applied Engineering and Technological Science (JAETS) 1.2 (2020): 70-76.

[18] Bukardi, E. S., \& Pambudi, W. S. Design and manufacture of a semi automatic T-shirt folding machine using the Fuzzy Proportional Derivative (FPD) method. Journal of Science and Informatics, 2017, $1(1), 34-44$.

[19] Pambudi, W. S., \& Pelawi, J. P. B. Simulation of Folding Machine with Pid, P, Pi, Pd and Fuzzy - Pd (Proportional Differential). Journal of Science and Informatics, 1 (1), 2015, Pp 25-33.

[20] Apriliyanto, M., Ulum, M., \& Joni, K. Semi Automatic T-Shirt Folding Machine Based on PID (Proportional Integral Derivative). Journal of Electronics, Electricity, Telecommunications, Computers, Informatics, Control Systems (J-Eltrik), 2020, 2 (1).

[21] Jianfeng Zeng and He bing, "Fold simulation methods based on differential domain for different clothing materials," 2016 IEEE Advanced Information Management, Communicates, Electronic and Automation Control Conference (IMCEC), Xi'an, 2016, pp. 12831287, doi: 10.1109/IMCEC.2016.7867419.

[22] Irawan, Y., Fernando, Y., \& Wahyuni, R. Detecting Heart Rate Using Pulse Sensor As Alternative Knowing Heart Condition. Journal Of Applied Engineering And Technological Science (JAETS),2019, $1(1), 30-42$.

[23] J. Maitin-Shepard, M. Cusumano-Towner, J. Lei and P. Abbeel, "Cloth grasp point detection based on multiple-view geometric cues with application to robotic towel folding," 2010 IEEE International
Conference on Robotics and Automation, Anchorage, AK, 2010, pp. 2308-2315, doi: 10.1109/ROBOT.2010.5509439.

[24] T. Watanabe, T. Kawamura, K. lizuka and S. Suzuki, "Development clothes folding system with small mobile robots," 2017 56th Annual Conference of the Society of Instrument and Control Engineers of Japan (SICE), Kanazawa, 2017, pp. 190-193, doi: 10.23919/SICE.2017.8105731.

[25] Wahyuni, Refni; Irawan, Yuda. Web-Based Heart Disease Diagnosis System With Forward Chaining Method (Case Study Of Ibnu Sina Islamic Hospital). Journal Of Applied Engineering And Technological Science (Jaets), 2019, 1.1: 43-50.

[26] Z. Zhao and Y. Zhou, "Clothing Fabric Automatic Recognition," 2018 10th International Conference on Intelligent Human-Machine Systems and Cybernetics (IHMSC), Hangzhou, 2018, pp. 24-27, doi: 10.1109/IHMSC.2018.00014.

[27] N. Silitonga, J. M. Hutapea, I. S. Dumayanti, A. N. N. Sianipar and S. Sitepu, "Design and Simulation of Automatic Folders," 2019 International Conference of Computer Science and Information Technology (ICoSNIKOM), Medan, Indonesia, 2019, pp. 1-4, doi: 10.1109/ICoSNIKOM48755.2019.9111491.

[28] D. Estevez, J. G. Victores, S. Morante and C. Balaguer, "Towards Robotic Garment Folding: A Vision Approach for Fold Detection," 2016 International Conference on Autonomous Robot Systems and Competitions (ICARSC), Braganca, 2016, pp. 188-192, doi: 10.1109/ICARSC.2016.65.

[29] Zeng Jianfeng and He Bing, "Fold simulation and optimization based on Laplacian coordinates for clothing," 2016 2nd IEEE International Conference on Computer and Communications (ICCC), Chengdu, 2016, pp. 1370-1375, doi: 10.1109/CompComm.2016.7924928.

[30] K. Salleh, H. Seki, Y. Kamiya and M. Hikizu, "Inchworm robot grippers in clothes manipulation - optimizing the tracing algorithm," 2007 International Conference on Intelligent and Advanced Systems, Kuala Lumpur, 2007, pp. 1051-1055, doi: 10.1109/ICIAS.2007.4658545.

[31] Yew Cheong Hou and K. S. M. Sahari, "Identifying corners of clothes using image processing method," 2010 International Conference on Intelligent and Advanced Systems, Manila, 2010, pp. 1-5, doi: 10.1109/ICIAS.2010.5716202. 